\section{Onychomycosis by Syncephalastrum racemosum: case report from Kerala, India}

\author{
Sabitha Baby, T.G. Ramya, R.K. Geetha \\ Department of Microbiology, Karuna \\ Medical College, Vilayodi, India
}

\begin{abstract}
We report a rare case of onychomycosis caused by Syncephalastrum racemosum in a 50 -year-old diabetic patient. The patient's nail was surgically excised and thorough debridement was done. The patient was successfully treated with topical nystatin.
\end{abstract}

\section{Introduction}

Zygomycosis is an acute or chronic infection caused by several fungi belonging to the phylum zygomycota. These saprophytic fungi are found ubiquitously in the environment. In the past, these fungi were traditionally considered as non pathogenic to humans and were treated as laboratory contaminants. In the present era, however, these fungi are emerging as highly opportunistic pathogens. ${ }^{1}$

Zygomycosis presents in six clinical forms, depending on the site involved: rhinocerebral, pulmonary, cutaneous, gastrointestinal, isolated renal and disseminated forms. ${ }^{1,2}$ The common fungi causing human disease are Rhizopus and Rhizomucor. ${ }^{3}$ Other agents include Absidia, Mucor, Saksenia, Cunninghamella and Syncephalastrum. ${ }^{4}$

Here, we report a case of onychomycosis caused by Syncephalastrum racemosum, a rarely encountered pathogen in humans.

\section{Case Report}

A 50-year-old laborer presented with pain and discoloration of left great toe nail since 15 days. She has history of injury to her left great toe nail since three months before, when she hit a stone accidentally while working. Initially the patient had no symptoms. After two days injury, the patient had noticed swelling of the toe and tenderness. The patient sought treatment in a local nursing home were symptomatic treatment was given. The patient was apparently normal till fifteen days back when she noticed yellowish discoloration and thickening of nail.

She had tenderness over the surrounding area. While enquiring her medical history, she was found to be a diabetic on treatment and her blood sugar was under control. On local examination there was tenderness over the toe, hyperkeratosis and onycholysis (Figure $1 \mathrm{~A})$.

Nail clippings and subungual debris was collected for microscopy and culture. The patient was referred to the surgeon who surgically excised her nail. The excised nail plate was sent to the Microbiology Laboratory for processing.

Potassium hydroxide mount from both the originally collected nail clippings and the surgically excised nail plate showed broad, hyaline, aseptate, ribbon like hyphae suggestive of one of the zygomycetes.

The nail clippings and the nail plate were inoculated on Sabouraud's Dextrose Agar and incubated at room temperature. After 48 hours, white aerial mycelia were found to grow. Lactophenol cotton blue mount from the growth showed broad, hyaline, aseptate ribbon like hyphae and fruiting bodies resembling Aspergillus. A slide culture was prepared and kept in moist chamber. After 48 hours, the cul-

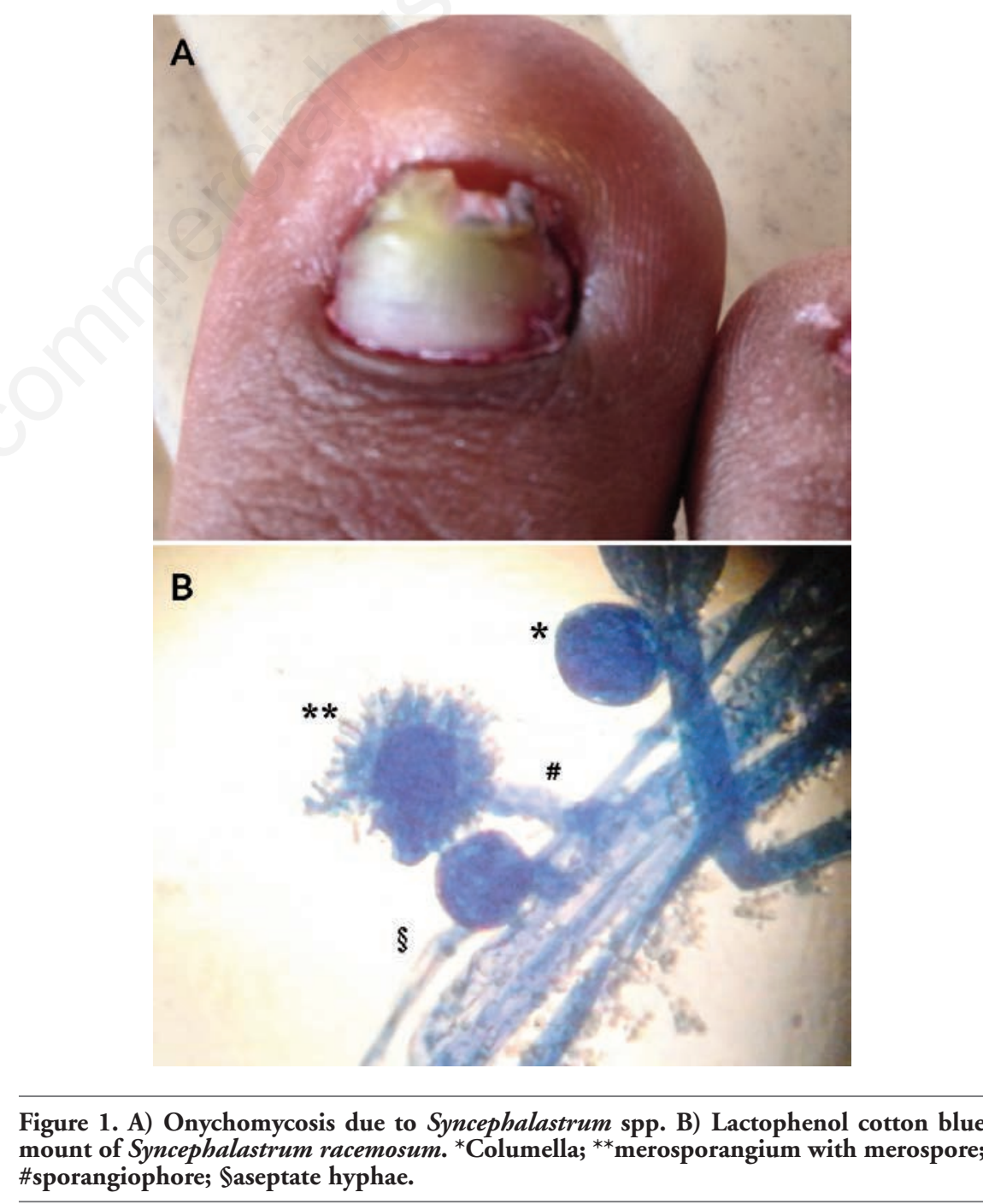

Figure 1. A) Onychomycosis due to Syncephalastrum spp. B) Lactophenol cotton blue mount of Syncephalastrum racemosum. *Columella; ** merosporangium with merospore; \#sporangiophore; \$aseptate hyphae.

Correspondence: T.G. Ramya, Department of Microbiology, Karuna Medical College, Vilayodi, Chittur, Palakkad, Kerala 678103, India.

Tel.: +91.4923.221790.

E-mail: tgramya@yahoo.com.

Key words: onychomycosis, Syncephalastrum racemosum.

Contributions: the authors contributed equally.

Conflict of interest: the authors declare no potential conflict of interest.

Received for publication: 24 June 2014.

Revision received: 12 January 2015.

Accepted for publication: 18 January 2015.

This work is licensed under a Creative Commons Attribution NonCommercial 3.0 License (CC BYNC 3.0).

CCopyright S. Baby et al., 2015

Licensee PAGEPress, Italy

Dermatology Reports 2015; 7:5527

doi:10.4081/dr.2017.5527 
Table 1. Differential diagnosis of Syncephalstrum sp. from other species.

\begin{tabular}{|c|c|c|c|}
\hline Property & Syncephalastrum sp. & Rhizopus sp. & Aspergillus sp. \\
\hline Phylum & Zygomycetes & Zygomycetes & Ascomycetes \\
\hline Colony morphology on SDA & $\begin{array}{l}\text { Cottony, fluffy, white to grey } \\
\text { becoming dark over time }\end{array}$ & $\begin{array}{l}\text { Cottony fluffy and grey in color: } \\
\text { lid lifters }\end{array}$ & Powdery yellow to green in color \\
\hline $\begin{array}{l}\text { Microscopy } \\
\text { lactophenol cotton } \\
\text { blue mount }\end{array}$ & $\begin{array}{l}\text { Hyphae: broad, irregular aseptate } \\
\text { hyphae, rhizoids rudimentary } \\
\text { sympodial branching. } \\
\text { Fruitingbodies: sporangiophore } \\
\text { end in gently swollen tip } \\
\text { called columella. } \\
\text { Long tubular pipe like sporangia } \\
\text { called merosporangia. } \\
\text { Chains of 5-10 spores within } \\
\text { each merosporangium (merospores). }\end{array}$ & $\begin{array}{l}\text { Ribbon like aseptate hyphae. } \\
\text { Prominent rhizoids, } \\
\text { no branching concave columella. } \\
\text { Single globose. } \\
\text { Sporangium. } \\
\text { Sporesare spherical equal in size. }\end{array}$ & $\begin{array}{l}\text { Narrow septate hyphae with } 45 \text { branching. } \\
\text { No rhizoids and no branching. } \\
\text { Spherical vesicle. No sporangium. } \\
\text { From the vesicle narrow extensions } \\
\text { called phialides on the tip spores called conidia. }\end{array}$ \\
\hline
\end{tabular}

ture was examined for sporogenesis or conidiation. Lactophenol cotton blue mount from the slide culture revealed sporangiophores with right angle branching. Sporangiophores terminated in to a columella with cylindrical merosporangia along the entire circumference (Figure 1B). The isolate was identified as Syncephalastrum racemosum. The patient was prescribed topical nystatin and discharged (Table 1) .

\section{Discussion}

Onychomycosis is traditionally referred to non-dermatophytic infection of the nail. ${ }^{1}$ The non-dermatophytic fungi associated with onychomycosis are Scopulariopsis, Acremonium, Aspergillus, Fusarium, Scytalidium and Geotrichum. ${ }^{5}$

Literature search reveals very few documented reports on Syncephalastrum infections. The only detailed report on cutaneous Syncephalastrum infection was published in 1980 in a 50 year old diabetic patient presenting with multiple draining sinuses. ${ }^{6} \mathrm{~A}$ case report of great toe nail onychomycosis by Syncephalastrum was published in 2004 where the patient was immunocompetent. ${ }^{7}$ Sclebuck et $a l^{5}$ described a case of invasive intra abdominal zygomycosis where the causative agent was reported to be Syncephalastrum racemosum. Sino-orbital zygomycosis by Syncephalastrum racemosum in a patient with hepatorenal disease was reported in 2008 from Mumbai. ${ }^{8}$ Syncephalastrum racemosum has been isolated from normal finger and toe nail clippings from several Egyptian students who had no clinical disease. Until now the debate continues whether this fungus can actually cause disease in humans. It is usually described as having low pathogenic potential in immunocompetent host. ${ }^{9}$

Preceding nail trauma is a known predisposing factor for non dermatophyte-mold onychomycosis. $^{10}$

Antifungals tested for efficacy against Syncephalastrum include amphotericin b, nystatin, pimoricin. ${ }^{11}$ The typical microscopic features combined with culture findings on two different occasions in the absence of any other fungal growth supports the pathogenicity of Syncephalastrum in our case.

\section{Conclusions}

Since Syncephalastrum racemosum closely mimicks Aspergillus in microscopy and is usually considered a contaminant, a high index of suspicion and systematic approach in accurate diagnosis is needed for the successful outcome of treatment.

\section{References}

1. Chander J. Textbook of medical mycology, 3rd ed. New Delhi: Mehta Publishers; 2011. pp 361-386

2. Rinaldi MG. Zygomycosis. Infect Dis Clin
North Am 1989;319-37.

3. Sugar AM. Mucormycosis. Clin Infect Dis 1992;14:126-9.

4. Schlebush S, Looke DF. Intraabdominal zygomycosis caused by Syncephalastrum racemosum infection successfully treated with partial surgical debridement and high dose Amphoptericin B Lipid complex. J Clin Microbiol 2005;43:5825-7.

5. Gupta AK, Ryder JE, Baran R, Summerbell RC. Non-dermatophyte onychomycosis. Dermatol Clin 2003;21:257-68.

6. Kamalam A, Thambiah AS. Cutaneous infection by Syncephalastrum. Sabouraudia 1980;18:19-20.

7. Pavlovic MD, Bulajic N. Great toenail onychomycosis caused by Syncephalastrum racemosum. Dermatol Online J 2006;12:7.

8. Baradkar VP, Mathur M, Panda M, Kumar S. Sino-orbital infection by Syncephalastrum racemosum in chronic hepatorenal disease. JOFMP 2008;12:45-7.

9. Ribes AJ, Vanover-Sams LC, Baker JB. Zygomycetes in human disease. Clin Microbiol Rev 2000;13:236-301.

10. Vander Straten RM, Balkis MM, Ghannoum AM. The role of nondermatophyte molds in onychomycosis: diagnosis and treatment. Dermatol Ther 2002;15:8998.

11. Otcenasek M, Buchta V. In vitro susceptibility to 9 antifungal agents of 14 strains of zygomycetes isolated from clinical specimens. Mycopathologia 1994;128:135-7. 